\title{
DIREITO FUNDAMENTAL À SAÚDE E A RESPONSABILIDADE DO ESTADO
}

\author{
Alexandre Walmott Borges ${ }^{1}$ \\ Giovanna Cunha Mello Lazarini Gadia ${ }^{2}$ \\ Mário Ângelo de Oliveira Júnior ${ }^{3}$
}

\begin{abstract}
RESUMO
Os direitos fundamentais consagrados historicamente são recepcionados e positivados pelo constituinte originário na Carta Magna de 1988, conferindo aos indivíduos uma posição jurídica de direito subjetivo, tanto no aspecto material quanto no seu aspecto processual. A consequência precípua dessa positivação constitucional é a limitação da liberdade de atuação dos órgãos do Estado e a exigência de sua ação na concretização efetiva destes direitos como condição essencial para a existência e consubstanciação do Estado Democrático de Direito. Nesse contexto, 0 presente trabalho tem como objetivo analisar o direito fundamental à saúde, previsto em enunciado normativo da Constituição Federal, cabendo ao Estado efetivá-lo através de mecanismos institucionalmente existentes, ressaltando-se a responsabilidade estatal diante das situações em que o acesso ao direito fundamental estudado é negado ao indivíduo. A referida análise será realizada observando os preceitos constituintes do Sistema Único de Saúde e o instituto da responsabilidade objetiva perante a atividade estatal.
\end{abstract}

Palavras-Chaves: Direito à Saúde. Direitos Fundamentais. Responsabilidade Objetiva. Sistema Único de Saúde. Serviços Públicos.

\section{INTRODUÇÃO}

A Constituição Federal de 1988 representou marco da concretização e constitucionalização dos direitos fundamentais na história do constitucionalismo brasileiro. O constituinte originário de 1988 apresentou o catálogo formal dos direitos fundamentais, presente no art. $5^{\circ}$ do texto constitucional. No entanto, possibilitou a adoção do conceito materialmente aberto de direitos fundamentais, consagrado pelo art. $5^{\circ} \S 2^{\circ}$ da Constituição da República, possibilitando ao interprete/aplicador visualizar espécies de direitos fundamentais no decorrer do texto constitucional.

Os direitos fundamentais sociais apresentados no art. 6ㅇ e em outros dispositivos constitucionais objetivam, precipuamente, assegurar mediante a compressão das desigualdades sociais, o exercício de uma liberdade real e efetiva, que pressupõem comportamento ativo do Estado. Nesta esteira o direito fundamental à saúde clama do Estado prestações de caráter essencialmente 
positivas, impondo ao Estado o dever de agir. Exigem-se, portanto, do Estado condutas ativas, tanto para proteção de certos bens jurídicos contra terceiros quanto para promoção ou garantia das condições de fruição desses bens.

Para tanto, a Constituição brasileira consagra o Sistema Único de Saúde como a instituição responsável pelo serviço público de saúde e as ações concernentes à sua realização, sendo, desta forma, o instrumento/mecanismo inaugural para se efetivar o direito fundamental à saúde e as obrigações dele decorrentes. Entretanto, a prestação dos serviços de saúde como atividade a ser organizada via dos esforços conjugados de todos os entes estatais, possibilitou à iniciativa privada transitar no mesmo setor, inclusive autorizando a atuação de empresas constituídas sob finalidade lucrativa.

A conclusão de que a prestação à saúde é direito fundamental garantido a todos pela Constituição Federal, demonstra a responsabilidade do agente estatal quando o mesmo, ou terceiros, lesar a referida garantia fundamental. Sendo assim, culminaria com configuração da responsabilidade civil do Estado, e a consequente obrigação de, diante de prestação inadequada ou de conduta estatal omissiva culposa ou dolosa, indenizar os danos causados pela ineficiência do serviço prestado. A lesão ao direito fundamental à saúde sofrida pelo indivíduo ou pela coletividade será o fator preponderante para configurar a responsabilização da conduta Estatal, configurando-se o instituto da responsabilidade objetiva. Todavia, será de suma importância compreender que somente deverá ser imputada responsabilidade ao ente estatal uma vez que se configurar a falha ou a deficiência na prestação do serviço de saúde.

\section{AS DIMENSÕES DOS DIREITOS FUNDAMENTAIS E O PROCESSO DE CONSTITUCIONALIZAÇÃO}

A doutrina apresenta o desenvolvimento dos direitos fundamentais em gerações/dimensões, uma consagração progressiva e sequencial dos textos constitucionais, baseada na ordem histórico-cronológica e nas conquistas alcançadas. Hodiernamente são observadas quatro dimensões como sequência de evolução do instituto. Isto porque, os direitos fundamentais não surgiram simultaneamente, mas em períodos distintos, resultado da realidade social de cada época e de maturação histórica em cada organismo social. Adotar a aquisição dos direitos fundamentais a partir da concepção de gerações indica, essencialmente, o caráter cumulativo da evolução desses direitos no tempo.

Os direitos fundamentais de primeira dimensão, relacionados ao tema liberdade defendido pelos revolucionários franceses, têm como titular o indivíduo. São os direitos e garantias individuais e políticos clássicos, oponíveis, em sua essência, ao Estado, impondo-Ihe um dever de abstenção (caráter negativo). Constata-se o surgimento das primeiras Constituições escritas, nas quais são 
consagrados os direitos fundamentais ligados aos valores liberdade, à vida, à propriedade e igualdade perante a lei, e os direitos de participação política, denominados de direitos civis e políticos.

Neste contexto presencia-se a busca da intervenção mínima do Estado frente aos anseios individuais da classe burguesa em ascensão e

os direitos fundamentais acabaram concebidos como limites para a atuação dos governantes, em prol da liberdade dos governados. Eles demarcavam um campo no qual era vedada a interferência estatal, estabelecendo, dessa forma, uma rígida fronteira entre o espaço da sociedade civil e do Estado, entre a esfera privada e a pública, entre o 'jardim e a praça'. Nesta dicotomia público/privado, a supremacia recaía sobre o segundo elemento do par, o que decorria da afirmação da superioridade do indivíduo sobre o grupo e sobre o Estado (SARMENTO, 2006, p. 12-13)

A concepção absenteísta do Estado liberal não respondia satisfatoriamente as novas exigências sociais. Neste contexto surgem os denominados direitos fundamentais de segunda dimensão, ligados a uma concepção de igualdade material. São os direitos sociais, econômicos e culturais, advindos da Revolução Industrial (Século XVIII), frutos dos constantes conflitos entre proletariados e os detentores dos meios de produção. Clama-se por prestações materiais e jurídicas exigíveis para a redução das desigualdades no plano fático de responsabilidade estatal.

Uma nova compreensão do relacionamento Estado/sociedade levou os Poderes Públicos a assumir o dever de operar para que a sociedade lograsse superar as suas angústias estruturais. Daí o progressivo estabelecimento pelos Estados de seguros sociais variados, importando intervenção na vida econômica e orientação das ações estatais por objetivos de justiça social (MENDES; COELHO; GONET, 2010, p.309)

A constitucionalização dos direitos sociais, culturais e econômicos inaugura a fase política do Estado do Bem-Estar Social, exigindo-se uma intervenção estatal na realidade privada. Sendo assim, não se espera uma conduta de abstenção (caráter negativo), mas sim uma prestação/comissão (caráter positivo) por parte do Estado. Ao Estado caberá, em diversas situações, colocar à disposição do indivíduo os meios materiais necessários para a conquista e manutenção de sua liberdade, através de uma postura ativa e não apenas de nãointervenção. Nesta esteira se enquadram os direitos fundamentais sociais da segunda dimensão, objetivo de estudo no capítulo posterior. Na garantia destes direitos, o que se busca não é a verificação da simples não-intervenção do Estado 
na esfera das liberdades individuais, mas o direito de participação no bem-estar social. O desenvolvimento destes direitos marca a atuação do Estado como executor da prestação positiva que garantirá a realização do direito fundamental.

Os direitos da terceira dimensão são característicos da concepção de fraternidade ou solidariedade, englobando o direito ao meio ambiente equilibrado, a saudável qualidade de vida e o direito de comunicação, dentre outros. São direitos que exigem a participação e colaboração de nações desenvolvidas e subdesenvolvidas. São compreendidos como direitos transindividuais - seus titulares são pessoas indeterminadas - destinados precipuamente à proteção do gênero humano.

Observa-se o surgimento do Estado Democrático de Direito. A concepção de um Estado Liberal de Direito e Estado Social de Direito são ultrapassadas, exigindo-se do ente soberano uma expressiva atuação transformadora da realidade jurídico-social. Para José Adércio Leite de Sampaio, os direitos fundamentais de terceira geração inspiram "a idéia de que somos todos habitantes de um mesmo e frágil mundo a exigir um concerto universal com vistas a manter as condições da habitabilidade para as presentes e futuras gerações" (SAMPAIO, 2004, p. 293).

A quarta dimensão de direitos fundamentais, recentemente defendida por alguns teóricos, está associada à pluralidade. São direitos como a democracia, a informação e o pluralismo. São resultados da globalização política e sua consequente inserção no sistema jurídico nacional. Segundo Paulo Bonavides

são direitos de quarta geração direito à democracia, o direito à informação e o direito ao pluralismo. Deles depende a concretização da sociedade aberta do futuro, em sua dimensão de máxima universalidade, para a qual parece o mundo inclinar-se no plano de todas as relações de convivência (BONAVIDES, 2006, p. 571-572).

O desenvolvimento da concepção de direitos fundamentais construído no decorrer das dimensões citadas possibilitou ao legislador constituinte a sua positivação e sistematização. Consequentemente, ao legislador ordinário, em sua atividade legiferante fica atribuída a necessidade de desenvolver e concretizar os anseios normativo-ideológicos previstos Carta Magna.

\section{BRASIL \\ 2 BREVES CONSIDERAÇÕES SOBRE DIREITOS FUNDAMENTAIS NO}


A expressão direitos fundamentais ("droits fondamentaux") surgiu na França (1770) no movimento político cultural que deu origem à Declaração dos Direitos do Homem e do Cidadão (1789). Na história constitucional brasileira os direitos fundamentais foram positivados em trinta e cinco incisos do art. 179 da Constituição do Império, outorgada em 25 de março de 1824. No entanto, a efetivação destes direitos previstos no título $8^{\circ}$ da inaugural Constituição apresentou significativo comprometimento, uma vez que o Poder Moderador conferia poderes constitucionalmente ilimitados ao Monarca.

A primeira Constituição Republicana brasileira, mantendo os direitos de sua antecessora apresentou significativos acréscimos normativos, tais como a constitucionalização do habeas corpus. Entretanto, a seção II do Título IV denominado - Declaração de Direitos - da Constituição Federal de 1891 não delimitou um catálogo expressivo dos direitos fundamentais. Ao contrário, limitouse ao caráter estritamente formal dos anseios individuais e coletivos.

Mesmo não se observando uma clara delimitação e concretização dos direitos fundamentais a Constituição de 1934 os reconheceu positivamente. Devido ao período histórico vivenciado pela população brasileira - governo do Presidente Getúlio Vargas - os direitos sociais foram amplamente elencados pelo texto constitucional, tais como os previstos no art.121 (salário mínimo, jornada de trabalho não superior a oito horas diárias, proibição do trabalho de menores de 14 anos de idade, do trabalho noturno ao menor de 16 anos e trabalho em indústria insalubre ao menor de 18, férias anuais remuneradas, indenização na demissão sem justa causa, dentre outros). As Constituições posteriores de 1946 e 1967/1969 não apresentaram significativas alterações normativo-ideológicas no que tange os direitos fundamentais.

A Constituição Federal de 1988 representou o marco da concretização dos direitos fundamentais na história do constitucionalismo brasileiro; todavia 0 constituinte de 1988 não apresentou sistematicidade quanto à respectiva classificação, acarretando impasses normativos e doutrinários. Isto em razão de a ausência de sistematicidade e em muitos casos a precária técnica legislativa do nosso texto constitucional não contribuir para uma classificação (SARLET, 2010, p.27). Busca-se por meio de uma delimitada classificação obter uma visão global e sistemática sobre o conjunto dos direitos fundamentais, adquirindo parâmetros objetivos para sua interpretação, enquadramento funcional e até mesmo a determinação do regime jurídico aplicável.

A Carta Magna de 1988 abrigou tanto em seu catálogo formal, quanto no decorrer do corpo textual, os direitos fundamentais, compreendidos estes como os direitos humanos consagrados e positivados na Constituição de cada país, frutos da ideologia característica de cada Estado Soberano. Os direitos fundamentais podem ser definidos como 
direitos público-subjetivos de pessoas (físicas ou jurídicas), contidos em dispositivos constitucionais e, portanto, que encerram caráter normativo supremo dentro do Estado, tendo como finalidade limitar o exercício do poder estatal em face da liberdade individual (DIMOULIS; MARTINS, 2009, p. 47)

O título II da Constituição da República apresenta disposição textual dos direitos fundamentais e garantias fundamentais, subdividindo-os em cinco capítulos: direitos individuais e coletivos; direitos sociais; nacionalidade; direitos políticos e partidos políticos.

Para Canotilho os direitos fundamentais têm como objetivo a

função de direitos de defesa dos cidadãos sob uma dupla perspectiva (1) constituem num plano jurídico-objetivo, normas de competência negativa para os poderes públicos, proibindo fundamentalmente as ingerências na esfera jurídica individual (2) implicam, num plano jurídico-subjetivo, poder de exercer positivamente direitos fundamentais (liberdade positiva) e de exigir omissões dos poderes públicos de forma a evitar: agressões lesivas por parte dos mesmos -liberdade negativa (CANOTILHO, 1993, p. 541)

O constitucionalista alemão Georg Jellinek em sua obra intitulada "Sistema dos Direitos Públicos", formulou concepção original de acordo com a qual o indivíduo vinculado ao Estado encontra sua posição a este cunhada por quatro espécies de situações jurídicas - status, seja com sujeito de deveres, seja como titular de direitos. A partir desta concepção Robert Alexy desenvolve sua teoria classificatória dos direitos fundamentais, segundo a função por eles exercida no ordenamento jurídico e a estrutura deôntica de suas normas, são estes divididos em três grandes grupos - os direitos a algo; as liberdades e as competências (OLSEN, 2010, p. 2010)

Data vênia a classificação apresentada por determinados teóricos, adotaremos no estudo em comento a classificação realizada por Ingo Wolfgang Sarlet, inspirado nos modelos classificatórios de Robert Alexy e Canotilho. Para o referido autor os direitos fundamentais, norteados por sua respectiva funcionalidade, são classificados em dois grandes grupos: direitos fundamentais de defesa e direitos fundamentais a prestação. Estes por sua vez subdividem-se em direitos a prestação em sentido amplo (direitos à proteção e direitos à participação na organização e nos procedimentos) e direitos a prestações em sentido estrito. 
Em que pese a importância de compreender cada aspecto da classificação ora apresentada, o foco de atenção e direcionamento do estudo voltam-se para os direitos fundamentais em sentido estrito, também denominados de direitos fundamentais sociais. Os direitos fundamentais sociais objetivam assegurar, mediante a compensação das desigualdades sociais, o exercício de uma liberdade e igualdade real/efetiva, que pressupõem o comportamento ativo do Estado. Neste contexto, Ingo Sarlet preleciona que

os direitos sociais de natureza positiva (prestacional) pressupõem seja criada ou colocada à disposição a prestação que constitui seu objetivo, já que objetivam a realização da igualdade material, no sentido de garantirem a participação do povo na distribuição pública de bens materiais e imateriais (SARLET, 2010, p. 284).

Os direitos de defesa caracterizam-se por exigir do Estado, preponderantemente, um dever de abstenção - característica negativa - em que se buscam limitações ao poder estatal frente a questões individuais e coletivas, típicos direitos de segunda dimensão.

Por outro lado, os direitos de prestações possuem um caráter essencialmente positivo, impondo ao Estado o dever de agir. Exigem-se do Estado condutas ativas, tanto para proteção de certos bens jurídicos contra terceiros quanto para promoção ou garantia das condições de fruição desses bens. Ocorre, destarte, de certa forma, a junção de preceitos supracitados. Os direitos de participação possuem caráter negativo/positivo, pois tem por função garantir o envolvimento individual na formação da vontade política da comunidade.

É de suma importância compreender o conceito dos direitos fundamentais a partir de um conceito materialmente aberto, consagrado pelo art. $5^{\circ} \S 2^{\circ}$ da Constituição da República, não adstrito ao catálogo formalmente apresentado pelo referido artigo. Os direitos fundamentais sociais não formam um grupo homogêneo no que se refere ao conteúdo e à positivação (KRELL, 2002, p. 21). Estes direitos objetivam assegurar, mediante a compressão das desigualdades sociais, 0 exercício de uma liberdade real e efetiva, que pressupõem um comportamento ativo do Estado. Neste diapasão, tanto o art. 6ำ quanto o art. 196 elencam o direito à saúde como um direito fundamental social.

A professora Cristina Queiroz, da Faculdade de Direito da Universidade do Porto, pesquisadora na área de direito constitucional, em sua obra "Direitos Fundamentais Sociais...", tem como foco a análise do direito constitucional português e adota como parâmetro de diálogo doutrinário e jurisprudencial o direito alemão. A referida autora defende que o objeto típico dos direitos fundamentais sociais vem constituído no chamado mínimo existencial material, 
como medida de menor grau de proteção (exemplo, saúde e educação). Ademais a pesquisadora portuguesa nos ensina que a técnica de positivação e constitucionalização dos direitos fundamentais sociais, que associa o reconhecimento de direitos à implementação de políticas de concretização desses direitos e garantias fundamentais, permite a eles um grau de justiciabilidade.

\section{de 1988 \\ 2.1 O direito fundamental à saúde e sua constitucionalização a partir}

Até meados do século $X X$ a saúde não era concebida como um direito do indivíduo e por isso não se obtinha em seu favor tutela específica do ente estatal relacionado a um direito fundamental. Assistência à saúde era prestada pelo Estado por razões estritamente econômicas, uma vez que se tratava de um fator negativo para a atividade produtiva. A Constituição da Itália de 1948 alterou o referido entendimento, conferindo a este direito tratamento específico de direito individual. Fator de importante contribuição normativa, mesmo sendo um dispositivo legal internacional, a Declaração Universal dos Direitos do Homem atribuiu, à saúde o status de elemento da cidadania ao prever que "toda pessoa tem direito a um nível de vida suficiente para lhe assegurar, e a sua família, a saúde e o bem-estar, principalmente quanto à alimentação, ao vestuário, ao alojamento, a assistência médica (...)". A partir deste momento o direito à saúde não é concebido apenas como uma prerrogativa estatal, reconhecido em plano exclusivamente institucional, mas sim como um direito do homem, clamando-se por disciplina própria/normativação específica.

Com a criação da Organização Mundial da Saúde (OMS) no ano de 1946, a saúde foi definida como o estado de completo bem-estar físico, mental e social e não simplesmente a ausência de doença ou enfermidade. Reconhecia-se, portanto como um direito fundamental a que todo ser humano deve ter acesso, independente de sua condição social ou econômica e de sua crença religiosa ou política.

Embora diversas críticas tenham sido sofridas pela definição da Organização Mundial da Saúde, em razão da mesma não ter levado em consideração a possibilidade de o Poder Público não possuir recursos disponíveis para garantir um completo bem-estar físico, mental e social aos indivíduos, tem-se aí um marco na delimitação da prestação positiva de responsabilidade do Estado.

No direito brasileiro a saúde somente foi tratada como matéria constitucional a partir da Constituição de 1934, que estabelecia, em seu art. 10, II, ser de competência executiva concorrente da União e dos Estados a organização de sua prestação. Por sua vez, o texto constitucional de 1937 aborda o tema da saúde como serviço público essencial da República, determinando ser de competência privativa da União a sua normatização, bem como de competência suplementar dos Estados a possibilidade de legislar acerca dos casos relacionados a saneamento básico, medidas profiláticas e organização de casa de 
saúde (artigos 16, XXVII e 16, c). A Carta de 1946 e a de 1967 seguiram a tendência do diploma constitucional anterior.

Consolidando o processo de evolução do sistema público de saúde, a Carta Magna de 1988 consagrou o acesso universal e igualitário aos serviços de saúde como um direito de cidadania. Desta forma, o direito à saúde passou a ter como seu garantidor o princípio da universalidade, sendo elevado ao nível de direito e garantia fundamental, norma dotada de eficácia plena. A questão da universalidade do direito à saúde é abordada pela professora Dinorá Adelaide Musetti Grotti de maneira esclarecedora:

Princípio da Generalidade ou universalidade: embora alguns o vejam como um princípio autônomo, é mais uma manifestação do princípio da igualdade, isto é, a possibilidade de que o serviço possa ser exigido e usado por todos. Significa que o mesmo deve atender, indistintamente, a todos que dele necessitem, independentemente do poder aquisitivo, satisfeitas as condições para sua obtenção. Sua manutenção constitui um dever legal, podendo ser exigido tanto daqueles que tenham a competência para instituí-lo quanto daqueles que o executem. (...) A prestação dos serviços públicos deve considerar as condições e diferenças dos usuários e a determinação da expansão dos serviços voltada para a consecução do atendimento universal, de modo a possibilitar o acesso a tais serviços a todos, independentemente das forças do mercado. (apud VIZEU, 2006, p. 115-116)

O direito fundamental social à saúde é apresentado pelo art. 196 da Carta Magna como um direito de todos e dever do Estado, garantido mediante políticas sociais e econômicas que visem à redução do risco de doenças e outros agravos e o acesso universal e igualitário às ações e serviços para sua promoção, proteção e recuperação.

Baseado no dispositivo normativo da Constituição Federal ora apresentado é mister a produção de algumas observações. Conforme apresentado, exige-se uma superação da teoria estrita de classificação das normas constitucionais em espécies preestabelecidas, realizadas por alguns doutrinadores, isto porque, ao compreender o disposto no art. 196 como uma norma de caráter estritamente programática, incapaz de produzir efeitos imediatos, somente indicando diretrizes a serem observadas pelo poder público, significaria negar a força normativa da Constituição (MENDES; COELHO; BRANCO, 2010, p.309). Nesta esteira, conforme nos ensina o jurista português, 
o direito à saúde é direito fundamental, dotado de eficácia e aplicabilidade imediatas, apto a produzir direitos e deveres nas relações dos poderes públicos entre si e diante dos cidadãos, superada a noção de norma meramente programática, sob pena de esvaziamento do caráter normativo da Constituição (CANOTILHO, 2010, p. 49)

Utilizando-se como paradigma o disposto no $5^{\circ}$, $\S 1^{\circ}$, da Constituição Federal, "as normas definidoras dos direitos e garantias fundamentais têm aplicabilidade direta", percebe-se que o mandamento normativo previsto no art. 196 é de caráter preceptivo, e não meramente programático, uma vez que os direitos fundamentais têm sua base na Constituição e não na lei, sendo direcionados a 'todos', atuando tanto como direito individual quanto direito coletivo. Mesmo sendo um direito clássico de segunda dimensão e possuindo caráter preponderantemente social é, sobretudo, um direito público subjetivo exigindo do Estado uma relação jurídica obrigacional.

Ao determinar ser um dever do Estado o artigo em comento estabelece que além do direito à saúde, há o dever fundamental de prestação da saúde por parte do Estado (compreendido como todos os entes federativos). Do ponto de vista federativo, a Constituição atribuiu competência para legislar sobre a proteção e defesa da saúde concorrentemente à União, aos Estados e Municípios (art. 24, XII, e 30, II, da Constituição Federal). Importante destacar que à União cabe o estabelecimento de normas gerais (art. 24, $\$ 1^{\circ}$ ); aos Estados, suplementar a legislação federal (art. 24, $2^{\circ}$ ); e aos Municípios, legislar sobre assuntos de interesse local, podendo igualmente suplementar a legislação federal e estadual, o que couber (art. 30, I e II).

O disposto no art. 23, II refere-se à competência comum em aspecto administrativo, cabendo aos entes da federação desenvolver políticas públicas que visem à redução de doenças, à promoção, à proteção e à recuperação da saúde, sendo, portanto, responsáveis solidários pela saúde junto ao indivíduo e à coletividade.

Em âmbito infraconstitucional o acesso à saúde está organizado em um complexo sistema que envolve a participação dos referidos entes federativos, que atuam em regime de direito público, bem como de entidades privadas, que tem sua atividade pautada ora pelo direito público, ora pelo privado. A norma do artigo 198 da Constituição Federal foi regulamentada em caráter infraconstitucional através da edição da Lei 8.080 de 19 de setembro de 1990, denominada de Lei Orgânica da Saúde. A lei estabelece a estrutura e o modelo operacional do Sistema Único de Saúde - SUS, apresentando sua forma de organização e de funcionamento. Nestes termos, Gilmar Mendes preleciona que "as ações e serviços de saúde são de relevância pública, integrantes de uma rede 
regionalizada e hierarquizada, segundo o critério da subsidiariedade, e constituem um sistema único" (MENDES; COELHO; BRANCO, 2010, p.833).

$\mathrm{O}$ art. $2^{\circ}$ da lei supracitada apresenta expressamente 0 direito à saúde como um direito fundamental, cabendo ao Estado prover as condições indispensáveis para seu pleno exercício e concretização. Típico direito de segunda dimensão, o direito à saúde, conforme legislação infraconstitucional diretamente relacionada ao dispositivo constitucional, clama do Estado uma ação prestacional positiva. Entretanto, é importante ressaltar que o dever estatal de prestação, no que tange o direito à saúde, não exclui o das pessoas, da família, das empresas e da sociedade (art. 2º ${ }^{\circ} \aleph^{\circ}$ da lei $8.080 / 90$ ). Isto porque, nas lições de Rogério Gesta Leal,

o direito à saúde não pode se concretizar, ou pelo menos não se concretiza somente através de uma política constitucional, eis que está é, prima facie, uma projeção imperativa sobre órgãos constitucionais do Estado das contingência de várias esferas da sociedade (LEAL, 2009, p. 164).

Desta forma, a Constituição brasileira consagra o Sistema Único de Saúde como a instituição responsável pelo serviço público de saúde e ações concernentes à sua realização, composto de uma rede regionalizada e hierarquizada, organizado em acordo com a descentralização, com direção única em cada esfera de governo, atendimento integral, conforme será melhor desenvolvido no item posterior.

\section{A GARANTIA À PRESTAÇÃO DE SAÚDE: CONSIDERAÇÕES SOBRE RESPONSABILIDADE DO PODER PÚBLICO PERANTE OS DISPOSITIVOS DA CONSTITUIÇÃO DE 1988.}

\subsection{O Sistema Único de Saúde como entidade reguladora, fiscalizadora e controladora da saúde no Brasil.}

O Sistema Único de Saúde é concebido como um conjunto de ações e serviços de saúde, prestados por órgãos e instituições públicas federais, estaduais e municipais, da Administração direita e indireta. Entretanto, a iniciativa privada poderá participar do Sistema Único de Saúde em caráter complementar. A lei 8.080/90 define o âmbito de atuação de cada ente federativo. No âmbito da União, a direção do Sistema Único Saúde ficará a cargo do Ministério da Saúde; nos Estados e no Distrito Federal, das Secretarias de Saúde ou de órgãos equivalentes; na esfera dos Municípios, da Secretaria de Saúde local ou de 
qualquer entidade correspondente (art. $9^{\circ}$ da Lei 8.080/90). Todavia, a referida lei se faz acompanhar de expressiva regulamentação administrativa realizada por meio de portarias editadas pelo Ministério da Saúde, com finalidade precípua de dinamizar e concretizar os objetivos buscados pela lei, característica da concepção de administração pública gerencial.

Conforme disposto no art. 195 da Constituição da República, o financiamento do Sistema Único de Saúde opera-se com recursos do orçamento da seguridade social dos entes da federação. Os recursos da Seguridade serão transferidos, primeiramente, ao Fundo Nacional de Saúde e, depois aos fundos de saúde dos entes locais (art. 34 e 35 da lei 8.080/90). Esses recursos devem ser depositados nos fundos de saúde de cada esfera de governo, e serão movimentados sob a fiscalização dos respectivos conselhos de saúde. A Emenda Constitucional $n^{\circ} 29$, de 13 de setembro de 2000, corroborando tal entendimento e visando dar maior estabilidade para os recursos de saúde, consolidou o mecanismo de co-financiamento das políticas de saúde pelos entes da Federação.

Em síntese, conforme preleciona Alexandre de Moraes, o art. 198 da Constituição Federal elenca as seguintes diretrizes e preceitos referente ao direito fundamental à saúde:

a) descentralização, com direção única em cada esfera de governo; b) atendimento integral com prioridade para as atividades preventivas, sem prejuízo dos serviços assistenciais; c) participação da comunidade; d) financiamento do Sistema Único de Saúde nos termos do art. 195, com recursos do orçamento da seguridade social, da União, dos Estados, do Distrito Federal e dos Municípios, além de outras fontes. A Emenda Constitucional $n^{\circ}$ 20/98 estabeleceu que a lei definirá os critérios de transferência de recursos para o sistema único da saúde e ações de assistência social da União para os Estados, o Distrito Federal e os Municípios, e dos Estados para os Municípios, observada a respectiva contrapartida de recursos (Constituição Federal, art. 195, § 10); e) liberdade na assistência à saúde para iniciativa privada; possibilidade de as instituições privadas participarem de forma complementar do Sistema Único de Saúde, segundo diretrizes destes, mediante contrato de direito público ou convênio, tendo preferência as entidades filantrópicas e as sem fins lucrativos; f) vedação à destinação de recursos públicos para auxílios ou subvenções às instituições privadas com fins lucrativos; g) vedação à participação direita e indireta de empresas ou capitais estrangeiros na assistência à saúde no país, salvo nos casos previstos em lei (MORAES, 2007, p. 779)

As ações e serviços de saúde são de interesse público, e, em razão disso, totalmente subordinados à regulamentação, fiscalização e controle do Poder REVISTA DO DIREITO UNISC, SANTA CRUZ DO SUL N ${ }^{\circ}$ 36|P. 95-119| JUL-DEZ 2011 
Público, nos termos da lei, que deve cumprir diretamente essas disposições ou ainda utilizar-se de terceiros, pessoas jurídicas de direito privado.

Toda atividade de regular, fiscalizar e controlar as ações e serviços de saúde é elencada pelo texto constitucional como de relevância pública, tornandose indubitável não ser somente uma faculdade a regulação social da saúde, mas um dever constitucionalmente atribuído à Administração Pública.

A Constituição da República apresenta o Sistema Único de Saúde como instituição responsável pelo serviço público de saúde. Entretanto, em seu art. 199, o texto constitucional prevê a possibilidade da existência de prestação dos serviços de saúde através da iniciativa privada, mediante contrato de direito público ou via de convênio, e desde que seguidas as diretrizes do Sistema Único de Saúde. Assim, autorizadas pela Constituição, poderão as instituições privadas participar de maneira complementar do Sistema Unico de Saúde na prestação de assistência, sendo, entretanto, vedada a destinação de recursos públicos para subvenções ou auxílios a quaisquer delas que tenham finalidade lucrativa.

Destarte, o setor da saúde está sempre subordinado à fiscalização e ao controle do Poder Público, mesmo nas situações em que o serviço esteja sendo prestado pela iniciativa privada.

\subsection{A organização dos setores prestadores do direito à saúde no Brasil: instituições públicas, privadas, saúde complementar e suplementar.}

Como mencionado anteriormente, a saúde no Brasil é de responsabilidade conjunta dos entes federativos e da sociedade, podendo em seu desenvolvimento atuar o setor público e também o setor privado. Segundo Leonardo Vizeu Figueiredo

"a organização Pan-Americana da Saúde (OPAS), órgão da Organização Mundial de Saúde, em relatório intitulado "A Saúde no Brasil", nos dá a seguinte lição sobre a atual configuração do sistema brasileiro de saúde: o sistema de serviços de saúde brasileiro está formado por uma rede complexa de provedores e financiadores, que abarca os segmentos público e privado. $O$ segmento público engloba os provedores públicos dos três níveis de governo, que no nível federal são o Ministério da Saúde (gestor nacional do SUS), os hospitais universitários do Ministério da Educação e os Serviços das Forças Armadas. Os níveis estadual e municipal compreendem a rede de estabelecimentos próprios das respectivas instâncias. A cobertura dos serviços públicos de saúde, complementada por serviços prestados por entidades privadas, contratadas pelo governo sob responsabilidade do SUS, 
chega a $75 \%$ da população. O segmento exclusivamente privado compreende os serviços lucrativos pagos diretamente pelas pessoas e as instituições provedoras de planos e seguros privados (VIZEU, 2006, p. 117)

Há, portanto, no atual cenário brasileiro os serviços públicos de saúde, custeados pelo Estado, prestados por instituições de direito público ou de direito privado, contratadas ou conveniadas junto ao Sistema Único de Saúde, bem como os serviços de assistência privada à saúde, custeados pelos particulares, prestados por instituições de direito privado.

Nos termos do artigo 199, $\$ 1^{\circ}$ da Constituição Federal, as instituições privadas poderão participar de forma complementar do Sistema Único de Saúde. Destarte, os entes privados que firmam contrato de direito público ou convênio com o SUS tornam-se integrantes do sistema público de saúde, ficando subordinados aos princípios orientadores do serviço público.

Diante desta premissa,

um hospital particular que celebra um contrato de prestação de serviços com o SUS deverá prestar assistência, integral e gratuita, sendo remunerado posteriormente pelo Poder Público, a todas as pessoas que para lá se encaminharem. Diz-se complementar porque essa participação das entidades privadas no SUS só ocorrerá quando o sistema público não possuir meios para suprir as necessidades da população, conforme previsão contida no art. 24 da Lei de Organização da Saúde (VIZEU, 2006, p. 119).

Não obstante tenha o legislador constituinte disciplinado a prestação dos serviços de saúde como atividade a ser organizada via dos esforços conjugados de todos os entes estatais, possibilitou à iniciativa privada transitar no mesmo setor, inclusive autorizando a atuação de empresas constituídas sob finalidade lucrativa. Assim, aqueles que quiserem tratamento diferenciado dos que são postos à disposição da coletividade pelo Estado poderão contratá-los com particulares, conforme dispositivo contido no artigo 199 da Constituição.

Como salientado, é o próprio texto constitucional que autoriza essa possibilidade através do dispositivo contido no artigo 199, caput, que admite que pessoas físicas e jurídicas de direito privado, tais como clínicas, hospitais e operadoras de planos de saúde prestem esses serviços mediante uma contraprestação dos interessados. Tal assistência é denominada suplementar, e é financiada exclusivamente por seus consumidores. A saúde suplementar pode ser definida como o regime participativo do particular nos serviços de saúde, sob 
forma facultativa ao beneficiário, com o intuito de ampliar o rol de serviços disponíveis ao indivíduo, ou ainda para suprir as lacunas do sistema público.

Tanto a prestação de saúde complementar quanto a suplementar são realizadas por entidades privadas. A instituição que presta serviço de saúde complementar segue as mesmas diretrizes e princípios do Sistema Único de Saúde; a entidade que perfaz atividades de saúde suplementar, por sua vez, regese por princípios de direito privado.

\section{A QUESTÃO DA RESPONSABILIDADE OBJETIVA DO ESTADO NAS SITUAÇÕES DE LESÃO NA GARANTIA DO DIREITO À PRESTAÇÃO DE SAÚDE.}

A conclusão de que a prestação à saúde é direito fundamental garantido a todos pela Constituição Federal nos leva a outros desenvolvimentos de igual relevância: de quem é a responsabilidade quando o agente estatal vem a lesar tal garantia fundamental? Quem assume os encargos quando o representante do Estado negligencia o bom atendimento ao indivíduo, acarretando-lhe prejuízos muitas vezes de ordem irreversível? Quais as situações em que ao Estado será imputada a obrigação de reparar prejuízos decorrentes do acesso precário ao direito fundamental à saúde? São esses questionamentos que agora passaremos a analisar.

\subsection{Considerações sobre o instituto da Responsabilidade.}

A ideia de responsabilidade decorre do fato de alguém dever ser chamado a responder perante o ordenamento jurídico em razão de fato praticado anteriormente. Segundo o administrativista José dos Santos Carvalho Filho,

(...) o fato e sua imputabilidade a alguém constituem pressupostos inafastáveis do instituto da responsabilidade. De um lado, a ocorrência do fato é indispensável, seja ele de caráter comissivo ou omissivo, por ser ele o verdadeiro gerador dessa situação jurídica (...). De outro, é necessário que o indivíduo a que se impute responsabilidade tenha a aptidão jurídica de efetivamente responder perante a ordem jurídica pela ocorrência do fato (CARVALHO FILHO, 2007, p. 471). 
A análise histórica do instituto da responsabilidade parte da noção de "irresponsabilidade". Em meados do século XIX, a noção que prevalecia no Ocidente era a de que o Estado não seria responsável por quaisquer atos praticados por seus agentes. O Estado liberal raramente interferia nas relações entre interesses individuais, e essa suposta isenção embasava a crença da de sua irresponsabilidade.

Essa teoria não prevaleceu por muito tempo, e seu abandono marca a adoção da doutrina da imputação de responsabilidade do Estado no caso de ação culposa de agente estatal, também denominada Teoria da Responsabilidade com Culpa. Tal teoria trazia em seu bojo a controversa necessidade de distinção dos atos de império e de gestão para que fosse ou não o Estado responsabilizado em sua conduta. Atos coercitivos decorrentes do poder soberano exercido pelo Estado, caracterizados como atos de império não gerariam responsabilidade de reparação por parte do ente estatal, em razão das normas tradicionais de direito público serem sempre protetivas da figura do Estado. Somente atos de gestão produzidos, que seriam mais semelhantes a atos do direito privado é que teriam a possibilidade de imputar responsabilidade ao Estado.

A confusão na interpretação da Teoria da Responsabilidade com Culpa facilitou sua substituição pela subsequente, denominada Teoria da Culpa Administrativa. Esse pensamento demonstra evolução do instituto da responsabilidade, e, na doutrina clássica de Paul Duez, "o lesado não precisaria identificar o agente estatal causador do dano. Bastava-lhe comprovar o mau funcionamento do serviço público, mesmo que fosse impossível apontar o agente que o provocou" (FERREIRA, 1985, p.78). Assim, a doutrina nomeou o fato como "falta do serviço", que podia se dar de três modos: Inexistência, mau funcionamento ou retardamento do serviço. Assim, para que o indivíduo lesado pudesse pleitear seu direito à reparação do prejuízo sofrido era necessário comprovar que o evento danoso resultava do mau funcionamento do serviço e que, via de consequência, teria o Estado atuado de forma culposa.

Após a queda da teoria da culpa no serviço, o direito moderno consagrou a teoria da responsabilidade objetiva do Estado. Na presente teoria percebe-se a dispensa da verificação da existência de culpa relacionada ao fato danoso efetivado. Assim, incide a teoria da responsabilidade objetiva sobre fatos lícitos e ilícitos do Estado, sendo suficiente que o interessado comprove o nexo causal entre o fato e o dano sofrido.

\subsection{A previsão constitucional de responsabilidade objetiva do Estado.}

A Constituição Federal de 1988 regula a matéria no artigo 37, §6º , que disciplina, in verbis: 
As pessoas jurídicas de direito público e as de direito privado prestadoras de serviços públicos responderão pelos danos que seus agentes, nessa qualidade, causarem a terceiros, assegurado o direito de regresso contra o responsável nos casos de dolo ou culpa.

Adota-se a noção da consagração da teoria da responsabilidade objetiva do Estado, admitindo-se que o dispositivo somente exige dolo ou culpa para o direito de regresso do Estado contra agente seu. Disso depreende-se que o texto constitucional abraça a teoria da responsabilidade objetiva do Estado e a da responsabilidade subjetiva do funcionário.

Segundo Maria Sylvia Zanella di Pietro,

a regra da responsabilidade objetiva exige, segundo o artigo 37, §º, da Constituição:

1) Que o ato lesivo seja praticado por agente de pessoa jurídica de direito público (...) ou pessoa jurídica de direito privado prestadora de serviço público (...);

2) Que as entidades de direito privado prestem serviço público, o que exclui as entidades da administração indireta que executem atividade econômica de natureza privada; as que prestam serviço público respondem objetivamente quando causem dano decorrente de sua prestação (...);

3) Que seja causado dano a terceiros em decorrência da prestação do serviço público; aqui está o nexo de causa e efeito $(\ldots)$;

4) Que o dano seja causado por agente das aludidas pessoas jurídicas, o que abrange todas as categorias, de agentes políticos, administrativos ou particulares em colaboração com a Administração (...);

5) Que o agente, ao causar o dano, aja nessa qualidade; não basta ter a qualidade de agente público, pois, ainda que o seja, não acarretará a responsabilidade estatal se, ao causar o dano, não estiver agindo no exercício de suas funções.

Diante dessas informações, tem-se que para que se configure a obrigação do Estado reparar ato lesivo causado por seus agentes há que se ter a presença do evento efetivamente configurado, o dano concreto e o nexo causal entre a ação do Estado e o prejuízo sofrido pelo indivíduo interessado. É a chamada Teoria do Risco Administrativo. E é por isso que se pode afirmar, paralelamente, que em situações de força maior, caso fortuito ou mesmo naquelas em que a vítima concorra exclusivamente para o resultado lesivo gerado não há que se falar em responsabilidade a ser imputada ao ente estatal. 


\subsection{Questionamentos sobre a imputação de responsabilidade aos Poderes Públicos diante de conduta lesiva comissiva e omissiva na garantia do acesso à saúde.}

A característica que marca a responsabilidade objetiva é a desnecessidade de o lesado pela conduta do Estado ter que comprovar a existência da culpa do agente ou do serviço. Constatando-se a presença de seus três pressupostos de existência - ocorrência do fato administrativo, dano e nexo causal entre os dois primeiros -, está presente a responsabilidade objetiva estatal.

O Estado pode vir a causar danos aos particulares por conduta comissiva ou omissiva. Quando o fato é comissivo, os danos são oriundos de conduta culposa ou não. A responsabilidade objetiva do Estado será consubstanciada, como dito acima, pela presença dos pressupostos que a caracterizam: fato administrativo, nexo causal e dano efetivo.

Entretanto, nas situações em que a conduta estatal for omissiva será necessário avaliar se a omissão caracteriza-se ou não por fato gerador de responsabilidade do Estado. Conforme ensinamento de José dos Santos Carvalho Filho,

nem toda conduta omissiva retrata um desleixo do Estado em cumprir um dever legal: se assim for, não se configurará a responsabilidade estatal. Somente quando o Estado se omitir diante do dever legal de impedir a ocorrência do dano é que será responsável civilmente e obrigado a reparar os prejuízos. A consequência, dessa maneira, reside em que a responsabilidade civil do Estado, no caso de conduta omissiva, só se desenhará quando presente estiverem os elementos que caracterizam a culpa. A culpa origina-se, na espécie, do descumprimento do dever legal, atribuído ao Poder Público, de impedir a consumação do dano (CARVALHO FILHO, 2007, p. 488).

Percebe-se então que a teoria da responsabilidade objetiva não encontra aí perfeita aplicabilidade, como ocorre quando a conduta do Estado é comissiva. O Estado, quando lesar direitos a partir de omissões, estará na posição comum a todos, tendo a análise de sua responsabilidade desenvolvida através da verificação de culpa.

No estudo da obra do ilustre autor, constata-se também que 
uma das hipóteses que, sem qualquer dúvida, evidenciam culpa em conduta omissiva da Administração é a que resulta em descumprimento de ordem judicial. (...) Quando não a descumprem, retardam o seu cumprimento, o que também revela omissão quanto a dever concreto de agir. Nesses casos o lesado tem direito de ser ressarcido pela Administração omissa (CARVALHO FILHOS, 2007, p.490).

No aspecto da responsabilidade do Estado em questões de saúde, Teresa Ancona Lopez menciona que

a responsabilidade pelos danos sofridos em hospitais públicos, bem como naqueles que têm convênio com o INSS deverá ser informada pela teoria objetiva, pois se trata de responsabilidade de agente do Poder Público (...). Este tipo de responsabilidade só é elidível com prova de caso fortuito ou de força maior, ou, ainda por falta de nexo causal entre o fato e o dano, como no caso de culpa exclusiva da vítima (CAHALI, 2007, p. 309-354).

Efetivamente,

para o reconhecimento da responsabilidade civil da entidade prestadora do serviço médico e assistencial parte-se do pressuposto da precariedade ou deficiência do serviço médico prestado (...) Assim: Responsabilidade civil do Estado - Nexo causal entre o fato danoso e o serviço público - morte de paciente de hospital público após ter sido precariamente atendido e liberado sem determinação de assistência doméstica ou ambulatorial - Indenização devida (CAHALI, 2007, 250).

A realidade é que, não obstante a regra da responsabilidade objetiva na atuação lesiva do Estado, esta somente deverá ser imputada se configurada a falha ou a deficiência na prestação do serviço médico-hospitalar,

posto como dever jurídico estatal e identificado como causa do evento danoso reclamado pela vítima ou por seus dependentes; a simples lesão incapacitante ou a morte do paciente inserem-se no risco natural do tratamento médico, ainda que prestado por agente do Estado, pois também aqui a recuperação do doente ou lesado não deixa de representar uma obrigação de meio e não de 
resultado. $\mathrm{O}$ que se pode admitir, em sede de responsabilidade civil da entidade estatal, é apenas uma presunção de que o agravamento da moléstia ou o perecimento do paciente tenham tudo a sua causa da deficiência, precariedade ou omissão do serviço médico-assistencial prestado pelo hospital (CAHALI, 2007, p.250).

Seguindo a tendência do até aqui elencado, a jurisprudência tem reconhecido a responsabilidade civil do Estado, e a consequente obrigação de, diante de prestação inadequada ou de conduta estatal omissiva culposa ou dolosa, indenizar os danos nos casos de morte e lesões por ele ocasionados. A lentidão no atendimento, desídia, imperícia e negligência na prestação do serviço médico em instituições públicas ou ao SUS conveniadas são algumas das condutas abordadas pelas jurisprudências transcritas e comentadas neste trabalho.

Ação de indenização - danos materiais e morais - responsabilidade civil do estado - imperícia, negligência de médico pediatra em hospital da rede fhemig - vítima criança que ficou tetraplégica pedidos procedentes - pensionamento mensal, custeio de tratamento e indenização por danos morais devidos. 1 Comprovado o nexo de causalidade entre os danos suportados pela autora, criança que ficou tetraplégica após ser atingida por pedaço do berço em que dormia em hospital da rede FHEMIG e a conduta negligente desta, impõe-se a sua condenação no pagamento de pensionamento mensal, no custeio dos tratamentos a que terá a autora de se submeter e aos danos morais que the foram causados. ${ }^{4}$

Analisando a ementa da decisão acima transcrita, percebe-se na linha de atuação do tribunal mineiro a aplicação da responsabilidade objetiva do Estado, em razão da conduta negligente do hospital público na figura de agente seu, que terminou por causar lesão de caráter irreversível na criança que necessitava do acesso ao direito fundamental estudado.

Diferente não é o posicionamento do tribunal goiano, que decidiu:

Apelação cível. Reparação de danos. Responsabilidade objetiva do Estado. Morte de recém-nascida pelo mau funcionamento do serviço público. Dano moral. Procedência. A responsabilidade civil do Estado, com base no risco administrativo, independe de culpa, bastando que seja demonstrado o nexo causal entre o fato e o dano, para se obter a reparação. À Administração resta demonstrar se a vitima concorreu com culpa ou dolo para o REVISTA DO DIREITO UNISC, SANTA CRUZ DO SUL No 36|P. 95-119| JUL-DEZ 2011 
evento; não provando, responde civilmente pela morte de recémnascida em razão da ineficiência do serviço hospitalar prestado, pela falta de UTI neonatal. A conduta omissiva do poder público, que tendo a missão de fornecer um serviço de saúde eficiente e não desempenha a contento o seu dever, conforme preceitua 0 artigo 196 da CF, gera o dever indenizatório que engloba o dano moral a ser fixado pelo magistrado, utilizando os critérios de proporcionalidade e razoabilidade. ${ }^{5}$

Mais uma vez percebe-se que a intervenção do Judiciário ocorreu no sentido de fazer valer a imposição da responsabilidade objetiva diante de conduta lesiva do Estado, que impediu o acesso ao direito fundamental à saúde pelos interessados, culminando com o óbito de recém-nascida causado pela insuficiência de meios eficientes a garantir a prestação devida.

Por fim, e ainda no mesmo campo de atuação, o Supremo Tribunal Federal reforma acórdão do Tribunal de Justiça do Estado de São Paulo fundando-se, para tanto, no instituto da responsabilidade objetiva do Estado:

Por ofensa ao art. $37, \S 6^{\circ}$, da CF/88, a Turma deu provimento a recurso extraordinário para reformar acórdão do Tribunal de Justiça do Estado de São Paulo que, entendendo não ter havido erro médico, ou seja, a culpa subjetiva do agente, mantivera a improcedência de ação de indenização por danos causados em razão de cirurgia realizada em hospital público por equipe médica composta de funcionários do Estado. Tratava-se, na espécie, de recorrente que, em razão de sequela permanente decorrente de procedimento cirúrgico - perda da visão do olho esquerdo em razão de cirurgia para correção de desvio do septo nasal -, ingressara com ação de indenização dos danos causados, em face do Hospital das Clínicas da Universidade de São Paulo, sob o fundamento da responsabilidade civil objetiva do Estado (CF, art. $\left.37, \S 6^{\circ}\right)$. Considerou-se que, sendo caso de responsabilidade objetiva, basta a comprovação do nexo de causalidade entre 0 dano e a intervenção cirúrgica, não havendo, na espécie, qualquer elemento que indique ter a vítima concorrido para o evento danoso. Entendeu-se, ainda, que o risco cirúrgico não exime o Estado, no âmbito da responsabilidade civil objetiva, do ressarcimento à vítima. Precedente citado: RE 178.806-RJ (DJU de 30.6.95). ${ }^{6}$

Depreende-se da análise desta última questão a desnecessidade de demonstrar nexo subjetivo que envolva culpa ou dolo do agente estatal para que se impute a responsabilidade de ressarcimento ao Estado. Basta, para que se configure a obrigação de indenizar, a efetiva ocorrência de evento lesivo causado 
por agente estatal no exercício de sua função. A clara lesão ao direito fundamental à saúde sofrida pela vítima é o fator preponderante na responsabilização da conduta do Estado.

\section{CONCLUSÃO}

O objeto abraçado no trabalho que ora se busca concluir é a saúde como direito fundamental constitucionalmente positivado, bem como a responsabilidade do Poder Público diante de situações em que o acesso a esta prerrogativa não é proporcionado ao indivíduo.

Após as considerações desenvolvidas no corpo do estudo, que ensejou delimitar o momento histórico-cronológico de surgimento do direito à saúde e, principalmente, de seu reconhecimento como um direito fundamental a ser garantido a toda coletividade, tratou-se de alocar a evolução do instituto no Brasil e sua abordagem pela Constituição de 1988, culminando com a análise da responsabilização objetiva do Estado nos diversos casos em que o acesso ao direito fundamental abordado é ineficaz, causando prejuízos ao indivíduo que dele necessita.

Diante dos questionamentos oferecidos, buscou-se ainda apresentar jurisprudência relacionada ao tema da responsabilidade, de forma a ilustrar o cenário em que se desenvolve o instituto nos tribunais brasileiros.

Concluindo o presente trabalho, tem-se que algumas considerações são relevantes para o encerramento da análise do tema. $O$ direito fundamental à saúde é classificado como "de segunda geração/dimensão", em razão de sua característica social, política e econômica; a evolução destes direitos de segunda dimensão marca a atuação do Estado como executor de uma prestação positiva, e não se limitando a uma postura de não intervenção. Percebe-se aí o movimento diverso do Estado atuando concretamente na garantia ao acesso do benefício da saúde à sociedade.

É somente a partir da Constituição de 1934 que o legislador brasileiro elenca a saúde como um direito fundamental. Entretanto, na Constituição de 1988 tem-se o verdadeiro marco de concretização do instituto, e, a partir de então, através da ação do SUS - Sistema Único de Saúde, se busca a organização da prestação e do acesso ao direito fundamental constitucionalmente garantido.

A Constituição Federal determina ser direito de todos e dever do Estado a garantia ao direito à saúde, mas autoriza que entidades privadas também prestem o serviço, mediante convênio ou contrato. Estas entidades, a despeito de atuarem por regime de direito público ou privado, são sempre subordinadas à fiscalização do Sistema Único de Saúde. 
A relação que se buscou analisar é aquela na qual o Poder Público, devendo oferecer o amplo e irrestrito acesso à saúde para os indivíduos da sociedade deixa de fazê-lo, por negligência, despreparo ou falta de recursos de seus agentes. Para estas situações, a Constituição Federal determina a aplicação da Teoria da Responsabilidade Objetiva que, salvo em situações de força maior, caso fortuito e culpa exclusiva da vítima acabará por imputar ao Estado a obrigação de reparar a lesão causada, independentemente de culpa ou dolo.

Nestes casos o que se pode perceber é uma atuação concreta do Poder Judiciário no sentido de fazer valer o clamor ao direito à saúde que deveria ter sido oferecido ao indivíduo, e a garantia de que o Estado reparará, ao menos financeiramente, os danos e prejuízos a ele causados.

Embora o direito à saúde seja hoje garantido constitucionalmente e diversos sejam os mecanismos de ação do Poder Público na busca de tornar esse acesso efetivo, em inúmeras situações a lesão à garantia constitucional ensejará a atuação do Poder Judiciário, que, diante do fato concreto, da existência da lesão e do liame causal entre os dois primeiros fatores, tratará de restabelecer a ordem e o equilíbrio entre as partes, obrigando o Estado à reparação do dano sofrido pelo individuo na busca pelo acesso ao direito fundamental à saúde.

\section{FUNDAMENTAL RIGHT TO HEALTH AND STATE RESPONSIBILITY}

\section{ABSTRACT}

The fundamental rights enshrined positivized historically and are greeted by the original constituents in the Magna Carta of 1988, giving individuals a subjective right of the legal position, both in the material and in its procedural aspect. With the consequence precípua limit freedom of action of State organs and demanding, the same, the effective realization of these rights as an essential condition for the existence and substantiation of the democratic rule of law. In this context, this study aims to examine the fundamental right to health, provided normative statement in the Constitution, while the State is to actualize it through existing institutional mechanisms, emphasizing the responsibility of the state face this fundamental social right. This analysis will be performed by observing the precepts of the constituents Health System and the Office of strict liability before the state action

Keywords: Right to Health. Fundamental Rights. Strict liability. Health System. Public Services. 


\section{NOTAS}

1. Doutor em Direito Público, pela Universidade Federal de Santa Catarina, Professor dos cursos de Graduação e Pós-Graduação (Mestrado) em Direito da Universidade Federal de Uberlândia. Professor dos Cursos de Graduação e Pós-Graduação (Mestrado) em Direito da Universidade Paulista Júlio de Mesquita

2. Advogada, pós-graduada em Direito Processual Civil e Direito Empresarial pela Universidade Federal de Uberlândia.

3. Advogado, graduado e pós-graduando em Direito da Administração Pública pela Universidade Federal de Uberlândia

4. TRIBUNAL DE JUSTIÇA DE MINAS GERAIS. 8 Câmara Cível. Apelação Cível. n. 750244527.2005.8.13.0024. Rel. Des. Elias Camilo.Votação unânime. Diário da Justiça 29/10/2009.

5. TRIBUNAL DE JUSTIÇA DE GOIAS. 2o Câmara Cível. Apelação Cível. n. 79807-4/188. Rel. Alfredo Abinagem. Votação não unânime. Diário da Justiça 23/06/2005.

6. Supremo Tribunal Federal. $2^{\circ}$ Turma. Recurso Extraordinário n. 217389. Rel. Min. Néri da Silveira. Votação unanime. Diário da Justiça 24/05/2002.

\section{REFERÊNCIAS}

BRASIL. Supremo Tribunal Federal. Disponível em: < http://www.stf.jus.br >. Acesso em 12. jan. 2010.

Tribunal de Justiça de Minas Gerais. Disponível em: < http://www.tjgo.jus.br >. Acesso em 11. jan. 2010.

. Tribunal de Justiça de Goiás. Disponível em: < http://www.tjmg.jus.br >. Acesso em 05. jan. 2010.

BONAVIDES, Paulo. Curso de Direito Constitucional. 19a ed., São Paulo: Malheiros, 2006.

CAHALI, YUSSEF SAID. Responsabilidade Civil do Estado. 3a ed., São Paulo, RT, 2006.

CARVALHO FILHO, José dos Santos. Manual de Direito Administrativo. 17 ed., Lumen luris: Rio de Janeiro, 2007.

DIMITRI, Dimoulis; MARTINS, Leonardo. Teoria geral dos direitos fundamentais. $2^{\circ}$ ed., São Paulo: Editora Revista dos Tribunais, 2009.

DI PIETRO, Maria Sylvia Zanella. Direito Administrativo. 21aㅡ ed., São Paulo, Atlas: 2008.

FIGUEIREDO, Leonardo Vizeu. Curso de Direito de Saúde Suplementar Manual Jurídico de Planos e Seguros de Saúde. MP Editora: São Paulo, 2006. 
LEAL. Rogério Gesta. Condições e Possibilidades eficaciais dos direitos fundamentais sociais: os desafios do poder judiciário no Brasil. Porto Alegre: Livraria do Advogado, 2009.

MENDES, Gilmar Ferreira. Direitos Fundamentais e Controle de Constitucionalidade. $3^{\mathrm{a}}$ ed., Saraiva: São Paulo, 2004.

MORAES, Alexandre de. Constituição do Brasil Interpretada e legislação constitucional. 6ª . ed., Atlas: São Paulo, 2006.

OLSEN, Ana Carolina Lopes. Direitos fundamentais sociais: efetividade frente à reserva do possível. Curitiba: Juruá, 2009.

QUEIROZ. Cristina. Direitos fundamentais sociais: funções, âmbito, conteúdo, questões interpretativas e problemas de justiciabiliadde. Coimbra: Coimbra Editora, 2006.

MELLO, Celso Antônio Bandeira de. Curso de Direito Administrativo. $22^{a}$ ed., Malheiros: São Paulo, 2007.

MENDES, Gilmar Ferreira; COELHO, Inocêncio Martins; BRANCO, Paulo Gustavo Gonet. Curso de Direito Constitucional. 5o ed., São Paulo: Saraiva, 2009.

SAMPAIO, José Adércio Leite. Direitos Fundamentais: Retórica e Historicidade. Belo Horizonte: Del Rey, 2004.

SARLET, Ingo Wolfgang. A eficácia dos direitos fundamentais - uma teoria geral dos direitos fundamentais na perspectiva constitucional. Porto Alegre: Livraria do Advogado, 2010.

SARMENTO, Daniel. Direitos Fundamentais e Relações Privadas. $2^{\underline{a}}$ ed., Rio de Janeiro: Lumen Juris, 2006.

SILVA, José Afonso da. Curso de Direito Constitucional Positivo. 23a ed., Malheiros: São Paulo, 2003.

SILVA, Júlio César Ballerini. Direito à Saúde - Aspectos práticos e doutrinários no direito público e no direito privado. Habermann, Leme, 2009.

Recebido para publicação: 05/07/2011

Aceito para publicação: 23/12/2011 